\title{
Perceptions of oral health adequacy and access in Michigan nursing facilities
}

\author{
Barbara J. Smith ${ }^{1}$, Elisa M. Ghezzi ${ }^{2}$, Michael C. Manz ${ }^{2}$ and Christiana P. Markova ${ }^{3}$ \\ ${ }^{1}$ Department of Periodontics and Oral Medicine, University of Michigan School of Dentistry, Ann Arbor, MI, USA and Council on Access, Press \\ Prevention, Interprofess Relations and Council on Access, Prevention, Interprofessional Relations, American Dental Association, Chicago, IL, \\ USA; ${ }^{2}$ Department of Cariology, Restorative Sciences, and Endodontics, University of Michigan School of Dentistry, Ann Arbor, MI, USA; \\ ${ }^{3}$ Division of Kinesiology, University of Michigan School of Literature, Science, and Arts, Ann Arbor, MI, USA
}

doi:10.1111/j.1741-2358.2007.00202.x

\section{Perceptions of oral health adequacy and access in Michigan nursing facilities}

Objective: To determine practices and perceived access barriers (facility resources, attitudes and professional dental involvement) related to oral health by surveying directors of nursing (DONs) in Michigan nursing homes (NHs).

Background: DONs are crucial to $\mathrm{NH}$ practice and policy, so understanding their perceptions of oral health care is vital.

Methods: A 27-item questionnaire exploring aspects of oral health was mailed to all 402 Michigan NH. Descriptive statistics were calculated for response items.

Results: Facility response rate was $32 \%(n=129)$. Sixty-three per cent of facilities had a written dental care plan primarily co-ordinated by nursing staff and social workers. Stationary dental equipment was available in $3 \%$ of facilities. Thirty-eight per cent stated an examination by a dentist was provided to new residents. Seventy-five per cent of residents identified as needing dental treatment were likely to receive it. Of the $28 \%$ of residents receiving dental treatment beyond an examination in the past year, $28 \%$ received emergent care. Over $50 \%$ of responding DONs indicated satisfaction with how oral hygiene needs were met in their facilities. The greatest perceived barriers were willingness of general and specialty dentists to treat residents at the nursing facility and/or their private offices as well as financial concerns of the resident and/ or family. Generally, greater resources were available in urban facilities, but substantial barriers to care were uniformly perceived.

Conclusion: Oral health policies and practices within Michigan NH vary, as measured by resources, attitudes, and the availability of professional care. Dental involvement in policy creation, provision of consultation, and service is limited.

Keywords: geriatric dentistry, oral health, nursing homes, barriers, survey.

Accepted 25 August 2007

\section{Introduction}

About 35.9 million people, $12 \%$ of the US population, are 65 years or older, 1.5 million Americans reside in nursing facilities, equivalent to approximately 41 per 1,000 population in the $65+$ age group $^{1}$. Projections estimate that by 2030 , the $65+$ population will exceed 72 million (US Census) ${ }^{2}$. As the number of older adults in the population increases, the number living in nursing facilities can be expected to increase as well.

Literature has described the compelling oral health needs of nursing home $(\mathrm{NH})$ residents.
Older adults living in nursing facilities tend to be at great risk for tooth loss, periodontal disease and attachment loss, caries, periapical pathology, soft tissue lesions, alveolar ridge resorption, and illfitting or missing dentures ${ }^{3-9}$. The impact of compromised oral health in the $\mathrm{NH}$ population is far from trivial with effects including diminished quality of life, impaired function and the potential for increased morbidity and mortality. The oral cavity can be a portal of entry for microbial infections that may result in severe, even lifethreatening consequences, such as aspiration pneumonia ${ }^{10}$. 
Dolan and Atchison ${ }^{11}$ described the frail and functionally dependent elders as having significant dental needs and experiencing greater barriers to receiving dental care than independent elders. Dental utilisation research highlights these barriers, reporting only one in five residents having had a dental visit in the last year ${ }^{12}$, with a mean time of 4.9 years since the last visit ${ }^{13}$. Key decision makers in long-term care facilities, such as directors of nursing (DONs), play a critical role in the development and implementation of resident care policy, including oral health care. Surveys in the United States and other countries have provided insights into how administrator and carer attitudes and perceptions may influence oral health care in their facilities. Low regard for the importance of oral health and its relationship to overall health was identified as a barrier to oral health promotion efforts in Switzerland and Australia ${ }^{14,15}$. A survey of Ohio $\mathrm{NH}$ executive directors revealed a discrepancy between perceived levels of oral health and satisfaction with oral care: $53 \%$ rated their residents' oral health as fair or poor but were still satisfied with the oral care provided at their facilities ${ }^{16}$. Similar inconsistencies were found by Berkey, et al. ${ }^{17}$ who reported that a majority of DONs in a nine-state study, were satisfied with their facility's ability to meet the oral health needs of residents, in spite of reporting levels of access significantly below that expected by dental professionals. In a survey of DONs in Nebraska, Johnson et al. ${ }^{18}$ found that only $36 \%$ of NHs had onsite dental services.

The goal of this paper was to report the results of a census survey of DONs in Michigan NHs regarding the status of oral health care in their facilities and barriers to improvement.

\section{Methods}

A listing of all licensed NHs in the State of Michigan was obtained from Michigan Master Data Archive at the University of Michigan (UM) Institute of Gerontology. Sufficient resources were available for the cross-sectional census survey of all 402 facilities using questionnaires mailed to the DONs. This (UM) IRB-approved study was funded by a UM Geriatrics Center grant through the Claude Pepper Older Americans Independence Center.

\section{Survey instrument}

The questionnaire was modified from a multi-state instrument developed and validated at the University of Colorado. The four-page questionnaire consisted of 27 close-ended items and explored different aspects of oral health. In addition to demographics, the survey addressed facility oral health barriers, resources, policies and procedures, and DONs' knowledge and perceptions.

\section{Study design}

Pilot testing and refinement of the survey instrument was achieved through input from selected $\mathrm{NH}$ administrators. One week prior to the questionnaire mailing, a postcard was sent advising facilities of the nature of the upcoming study. In addition to the four-page questionnaire, the mailed packet included (i) a cover letter from the UM researchers, (ii) a letter of support from the Michigan Association of Homes and Services for the Aging, and (iii) a stamped return envelope. A reminder postcard was sent 1 week after the questionnaire. Efforts were made to ascertain the existence and correct address of NHs for which the mailings were returned from the post office due to incorrect or non-existent addresses. Additional questionnaires were sent as appropriate for these facilities or when NHs requested replacement of misplaced forms.

\section{Data management and analysis}

Data collection took place between November 2005 and January 2006. To ensure anonymity, all returned questionnaires were assigned an identification number. Data from returned surveys were double-entered into a Microsoft Office Access 2003 database software (Microsoft Corporation, Redmond, WA, USA). Discrepancies from the double entry were corrected and where possible, data were further cleaned by resolving inconsistencies in responses. Data were analysed with Statistical Analysis Software (Version 9.1; SAS Institute Inc., Cary, NC, USA). Descriptive statistics were generated to characterise the population of $\mathrm{NH}$ in the state of Michigan. Respondent estimates were used to calculate overall mean percentages where applicable.

This article presents univariate and bivariate distributions of results for categorical and continuous response items in the questionnaire. Many comparisons by urbanicity are included. The urbanicity variable used for comparison was based on Rural Urban Commuting Area (RUCA) codes. For these comparisons a dichotomous variable was used: 'Metropolitan' ( $\geq 50$ 000) and 'Micropolitan' (10 000-49 999) RUCA categories represented urban areas, and 'Small Town' (2500-9999) and 'Rural' (commuting flow not to an Urbanised Area or Urban Cluster) RUCA categories represented rural areas. 
With questionnaires sent to all $\mathrm{NH}$ in the state, this project represents a point in time census study of Michigan nursing facilities. Furthermore, Michigan NHs represent a unique population of facilities. Therefore, the responding facilities cannot be interpreted as representing a random sample of $\mathrm{NH}$ from a larger population of such facilities, e.g. in other states or nationally. The presentation of the descriptive analysis is based on the theoretical statistical argument that the estimates and differences presented for our target population at the point in time that the survey was conducted are not subject to sampling error. Therefore, statistical precision estimates and tests of differences, which are based on the assumption of sampling error associated with random sampling from a population, are not included.

There is possible error in the results because of measurement error and non-response bias. The presence and extent of effects of non-response bias and measurement error are evaluated to the extent possible with available information and data. Comparisons of the responding NHs to NHs in the state and nationally have been included to assess the potential for non-response bias.

\section{Results}

Completed questionnaires were returned by 129 of the 402 surveyed facilities, a 32\% return rate (Table 1). Based on the reported average facility census from responding facilities and available state data, the responding NHs represented about 12797 $(30.2 \%)$ of the approximately 42400 total NH residents in the state. Seventy-one per cent of the questionnaires were completed by the targeted personnel group, DONs. Characteristics of the respondent nursing facilities are reported in Table 1. Differences between facilities in urban and rural locations were found in mean facility bed size, mean daily census, percentage of private pay residents, ethnic distribution, percentage of facilities in multi-

Table 1 Characteristics of respondent nursing facilities in the state of Michigan census survey with comparable state of Michigan and United States characteristics.

\begin{tabular}{|c|c|c|c|c|c|}
\hline & \multicolumn{3}{|l|}{ Survey results } & \multirow[b]{2}{*}{ Michigan } & \multirow[b]{2}{*}{ United States $^{\mathrm{a}}$} \\
\hline & Overall & $U_{r b a n^{b}}$ & Rural $^{\mathrm{b}}$ & & \\
\hline $\begin{array}{l}\text { Michigan NH/Surveys } \\
\text { mailed, } n\end{array}$ & 402 & 314 & 88 & 402 & 18000 \\
\hline Surveys received (\%) & $129(32)$ & $89(74)$ & $32(26)$ & $\begin{array}{l}\text { Urban: } 78 \% \\
\text { Rural: } 22 \%\end{array}$ & $\begin{array}{l}\text { Metropolitan } \\
\text { statistical area: } 61 \%\end{array}$ \\
\hline Response rate & $32 \%$ & $28 \%$ & $36 \%$ & & $\begin{array}{l}\text { Nonmetropolitan } \\
\text { statistical area: } 39 \%\end{array}$ \\
\hline Facility Size (no. beds), mean \pm SD & $107 \pm 54$ & $114 \pm 56$ & $86 \pm 40$ & 114 & 105 \\
\hline Daily census (no. beds), mean \pm SD & $99 \pm 50$ & $105 \pm 53$ & $80 \pm 37$ & & \\
\hline $\begin{array}{l}\text { Funding/payer source: \% private } \\
\text { pay, mean } \pm \text { SD }\end{array}$ & $13 \pm 15$ & $16 \pm 16$ & $8 \pm 9$ & & \\
\hline \multicolumn{6}{|l|}{ Status } \\
\hline For-profit/proprietary, \% & 46 & 45 & 44 & 66 & 67 \\
\hline Ethnicity: \% Caucasian, mean \pm SD & $88 \pm 20$ & $86 \pm 21$ & $96 \pm 10$ & 79 & 88 \\
\hline \multicolumn{6}{|l|}{ Organisation } \\
\hline Multiple facilities, \% & 49 & 52 & 42 & & 60 \\
\hline No. facilities, mean \pm SD & $19 \pm 30$ & $18 \pm 35$ & $21 \pm 19$ & & \\
\hline $\begin{array}{l}\text { Dental insurance part of employee } \\
\text { employment benefits, } \%\end{array}$ & 84 & 86 & 77 & & \\
\hline \multicolumn{6}{|l|}{ Person completing survey } \\
\hline Director of Nursing, $n(\%)$ & $90(71)$ & $62(70)$ & $23(72)$ & & \\
\hline Social worker, $n(\%)$ & $21(16)$ & $14(16)$ & $6(18)$ & & \\
\hline Administrator, $n(\%)$ & $5(4)$ & $4(5)$ & $1(3)$ & & \\
\hline Other ${ }^{\mathrm{c}}, n(\%)$ & $11(9)$ & $8(9)$ & $2(6)$ & & \\
\hline
\end{tabular}

${ }^{\text {a Jones }}{ }^{27}$.

${ }^{\mathrm{b}}$ Eight facilities did not report or had invalid zip codes. These could not be identified as urban or rural.

${ }^{\mathrm{c} O}$ Other titles/roles: Admissions; Office Manager; Customer Service; Inservice Co-ordinator; Director of Clinical Services; Care Co-ordinator. 
ple-facility organisations, and number of facilities offering dental insurance employment benefits.

Table 2 characterises the policy and personnel that provide care planning and assess resident oral health. Most of the facilities $(63 \%)$ had a written dental care plan and these were more often reported in rural facilities than urban (73\% vs. 58\%). Dental professionals had assisted in the development of the written care plans in only $16 \%$ of the facilities having written plans of care. The positions primarily responsible for co-ordinating the plan of care were social workers and unit charge nurses.

The availability of oral health resources used for resident care is summarised in Table 3. Overall, 73\% of the respondents reported provision of dental treatment within their facilities with $70 \%$ of care delivered using portable equipment brought into the facilities by dental providers. Urban areas were more

Table 2 Policy and personnel responsible for oral health of residents.

\begin{tabular}{|c|c|c|c|}
\hline & \multicolumn{3}{|c|}{ State of Michigan } \\
\hline & Overall & Urban & Rural \\
\hline \multicolumn{4}{|l|}{$\begin{array}{l}\text { Facility's plan of care for } \\
\text { oral health }\end{array}$} \\
\hline $\begin{array}{l}\text { Percentage of facilities } \\
\text { with written plan }\end{array}$ & 63 & 58 & 73 \\
\hline $\begin{array}{l}\text { Percentage of written plans } \\
\text { drafted with dental } \\
\text { professional assistance }\end{array}$ & 16 & 16 & 14 \\
\hline \multicolumn{4}{|l|}{$\begin{array}{l}\text { Primary responsibility for } \\
\text { day-to-day co-ordination of } \\
\text { dental plan of care }(\%)\end{array}$} \\
\hline Social worker & 44 & 45 & 38 \\
\hline Unit charge nurse & 16 & 14 & 22 \\
\hline $\begin{array}{l}\text { Facility administrator/ } \\
\text { administration }\end{array}$ & 13 & 14 & 9 \\
\hline Other nurse & 13 & 15 & 12 \\
\hline Director of nursing & 12 & 10 & 19 \\
\hline Dentist & 2 & 2 & 0 \\
\hline \multicolumn{4}{|c|}{$\begin{array}{l}\text { Person typically performing MDS* } \\
\text { assessment of 'oral/nutritional } \\
\text { status' }(\%)\end{array}$} \\
\hline Other nurse & 50 & 52 & 41 \\
\hline Dietician & 43 & 41 & 53 \\
\hline Unit charge nurse & 5 & 3 & 6 \\
\hline Director of nursing & 2 & 1 & 3 \\
\hline \multicolumn{4}{|c|}{$\begin{array}{l}\text { Person typically performing MDS* } \\
\text { assessment of 'oral/dental } \\
\text { status' }(\%)\end{array}$} \\
\hline Other nurse & 58 & 60 & 47 \\
\hline Dietician & 35 & 36 & 41 \\
\hline Unit charge nurse & 5 & 3 & 9 \\
\hline Director of nursing & 2 & 1 & 3 \\
\hline
\end{tabular}

*Minimum Data Set. likely to have in-house dental treatment than their rural counterparts $(84 \%$ vs. $34 \%)$. Forty-one per cent of urban facilities and $30 \%$ of facilities located in rural areas reported that new residents would be examined by a dentist upon admission to the facility. Over one half of the longer stay residents (1 year or more) were considered likely to receive an annual oral examination by a dental professional $159 \%$ in urban vs. $41 \%$ in rural locations). Among the reported $80 \%$ of residents requiring assistance with oral care, an average of 11 min of supervision or assistance with personal oral hygiene activities were reported to be provided.

Responses to identified need for dental care and the types of treatment provided are summarised in Table 4 . Survey participants indicated that $75 \%$ of residents who were identified as needing dental care by a dentist or dental hygienist would actually receive treatment. Only $28 \%$ of all residents were likely to have received dental treatment beyond an examination in the past year. Emergency dental care accounted for approximately a quarter of the care provided.

A hypothetical resident experiencing acute dental discomfort, due to an abscessed tooth or gums, was the object of three questions that sought to identify facility response to a resident with oral pain. The majority of the respondents $(85 \%)$ felt that the individual would not receive care within $24 \mathrm{~h}$ from the identification of the problem. Over three quarters believed that a general dentist would be the most likely professional to provide treatment. Dissatisfaction with the facility response to this hypothetical resident's oral pain was indicated by only $27 \%$ of survey participants.

Satisfaction with other aspects of oral health care practices in the facilities surveyed is summarised in Table 5. Over half expressed being satisfied ('very' or 'somewhat') with the way that oral hygiene needs were met at $\mathrm{NH}$ facility. Satisfaction with the quality of dental treatment provided by dental professionals at their facilities was high, with $75 \%$ of respondents indicating being either 'very' or 'somewhat' satisfied.

A series of 14 potential barriers to good oral health were listed. Respondents were asked to scale the significance of barriers from ' 0 ' not significant to ' 5 ' highly significant. Table 6 provides percentages of respondents who ranked the barriers to care as 3 or greater. The greatest barriers perceived by respondents were willingness of general dentists and specialty dentists to treat residents at the nursing facility and private office, as well as financial concerns of the resident and/or family. Items not considered significant barriers included 
Table 3 Oral health resources provided for residents.

\begin{tabular}{|c|c|c|c|}
\hline & \multicolumn{3}{|c|}{ State of Michigan } \\
\hline & Overall & Urban & Rural \\
\hline \multicolumn{4}{|l|}{ Type of dental equipment utilised for resident care (\%) } \\
\hline Dental treatment provided at facility & 73 & 84 & 34 \\
\hline Portable dental equipment & 70 & 82 & 31 \\
\hline Stationary/built-in dental equipment & 3 & 2 & 3 \\
\hline $\begin{array}{l}\text { Beyond MDS assessment, per cent of facilities providing new } \\
\text { residents a more detailed screening or examination by a dentist (\%) }\end{array}$ & 38 & 41 & 30 \\
\hline $\begin{array}{l}\text { Percentage of those in residence for one or more years who are } \\
\text { likely to receive an annual oral examination by a dental } \\
\text { professional, mean } \pm \text { SD }\end{array}$ & $55 \pm 35$ & $59 \pm 33$ & $41 \pm 37$ \\
\hline \multicolumn{4}{|l|}{ Oral health most likely to be monitored by $(\%)$} \\
\hline Visual assessment by a staff member & 44 & 41 & 44 \\
\hline Screening examination by a dentist or dental hygienist & 18 & 23 & 9 \\
\hline Verbal query of resident by a staff member & 38 & 36 & 47 \\
\hline $\begin{array}{l}\text { Percentage of residents who required supervision or assistance with } \\
\text { personal oral hygiene activities during past seven days, mean } \pm \text { SD }\end{array}$ & $80 \pm 17$ & $81 \pm 17$ & $79 \pm 18$ \\
\hline $\begin{array}{l}\text { Average number of staff member minutes per resident spent providing } \\
\text { supervision or assistance on a given day, mean } \pm \text { SD }\end{array}$ & $11 \pm 7$ & $10 \pm 7$ & $11 \pm 8$ \\
\hline
\end{tabular}

Table 4 Dental treatment provided for residents.

\begin{tabular}{|c|c|c|c|}
\hline & \multicolumn{3}{|c|}{ State of Michigan } \\
\hline & Overall & Urban & Rural \\
\hline $\begin{array}{l}\text { Percentage of residents identified as needing dental care who are likely to } \\
\text { receive treatment, mean } \pm \mathrm{SD}\end{array}$ & $75 \pm 31$ & $77 \pm 29$ & $64 \pm 36$ \\
\hline $\begin{array}{l}\text { Percentage of all residents in facility who received dental treatment beyond } \\
\text { an examination in past } 12 \text { months, mean } \pm \text { SD }\end{array}$ & $28 \pm 24$ & $30 \pm 25$ & $19 \pm 14$ \\
\hline \multicolumn{4}{|l|}{ Percentage of dental care that was considered: } \\
\hline Emergency, mean \pm SD & $28 \pm 36$ & $26 \pm 34$ & $38 \pm 42$ \\
\hline Routine, mean $\pm \mathrm{SD}$ & $65 \pm 36$ & $70 \pm 33$ & $48 \pm 38$ \\
\hline \multicolumn{4}{|l|}{$\begin{array}{l}\text { When would a hypothetical resident with acute dental discomfort most } \\
\text { likely be treated by a dentist? }(\%)\end{array}$} \\
\hline Immediately & 3 & 1 & 9 \\
\hline Within $24 \mathrm{~h}$ & 12 & 15 & 6 \\
\hline Within $1-3$ days & 38 & 36 & 47 \\
\hline Within 4-7 days & 25 & 25 & 22 \\
\hline Longer than 7 days & 18 & 19 & 9 \\
\hline Dentist would not typically be involved & 4 & 3 & 6 \\
\hline \multicolumn{4}{|l|}{$\begin{array}{l}\text { If the hypothetical resident were treated outside the facility, what is the most } \\
\text { likely treatment setting? }(\%)\end{array}$} \\
\hline General dentist's private office & 77 & 75 & 84 \\
\hline Specialist dentist's private office & 13 & 14 & 9 \\
\hline Hospital emergency department & 10 & 11 & 6 \\
\hline \multicolumn{4}{|l|}{$\begin{array}{l}\text { Are you satisfied with the way your facility would probably help with the } \\
\text { hypothetical resident? }(\%)\end{array}$} \\
\hline Very satisfied & 28 & 29 & 29 \\
\hline Somewhat satisfied & 45 & 44 & 45 \\
\hline Somewhat dissatisfied & 21 & 22 & 16 \\
\hline Very dissatisfied & 6 & 4 & 10 \\
\hline
\end{tabular}


lack of interest in dental care by resident or resident's family, and apathy of dental consultants, facility administrators or staff.

\section{Discussion}

The presence of a policy, the availability and commitment of resources, and the knowledge and

Table 5 Administrator knowledge and perceptions.

\begin{tabular}{lccc}
\hline \multicolumn{4}{c}{ State of Michigan } \\
\cline { 2 - 4 } & Overall & Urban & Rural \\
\hline \multicolumn{4}{c}{ Prompt treatment of resident dental problems } \\
would prevent serious illness (\%) & \\
Definitely yes & 49 & 49 & 53 \\
Probably yes & 44 & 44 & 41 \\
Probably no & 7 & 7 & 6 \\
Definitely no & 0 & 0 & 0 \\
Satisfaction with the way the oral hygiene & \\
needs of resident are met at the facility (\%) & \\
Very satisfied & 9 & 9 & 9 \\
Somewhat satisfied & 48 & 51 & 44 \\
Somewhat dissatisfied & 35 & 31 & 41 \\
Very dissatisfied & 8 & 9 & 6 \\
Satisfaction with the quality of dental treatment & \\
provided by dental professionals at the facility & $(\%)$ \\
Very satisfied & 26 & 20 & 38 \\
Somewhat satisfied & 49 & 52 & 44 \\
Somewhat dissatisfied & 19 & 24 & 9 \\
Very dissatisfied & 5 & 5 & 9 \\
\hline
\end{tabular}

perceptions of decision makers are important elements for addressing the oral health needs of the $\mathrm{NH}$ population; however, professional dental involvement is also essential. The results of this survey demonstrate that professional dental involvement in long-term care is limited and varies by locale. Facility plans of care for oral health are being developed largely without the input of the dental profession. Dental professionals do not evaluate resident oral status on admission, nor are such examinations ever occurring in $60 \%$ of responding facilities.

Upon admission to a long-term care facility and at regular intervals thereafter, $\mathrm{NH}$ residents receive a comprehensive assessment that employs the Minimum Data Set (MDS). The use of this assessment tool is mandated by the federal government (OBRA 1987) ${ }^{19}$ for all facilities that receive either Medicaid or Medicare reimbursement. Two sections of the MDS specifically address oral health issues such as chewing or swallowing problems, mouth pain, oral cleanliness, condition of gum tissue, etc. Results from this survey indicate that nursing personnel and dieticians primarily perform the oral-related portions of the MDS. The inadequacy of the MDS to accurately identify oral health problems has been described by Thai et al. ${ }^{20}$ who found that nurses' MDS assessments identified few oral health problems and those problems identified did not translate into dental treatment. Ettinger et $a l^{21}$ reported that only $9 \%$ of DONs in Iowa found the MDS useful in identification of dental

Table 6 Perceived barriers to oral health for residents $(n=129)$.

\begin{tabular}{|c|c|c|c|}
\hline Barrier & Overall $(\%)^{\mathrm{a}}$ & Urban $(\%)^{\mathrm{a}}$ & Rural $(\%)^{\mathrm{a}}$ \\
\hline $\begin{array}{l}\text { Willingness of specialty dentist (like an oral surgeon or denture specialist) } \\
\text { to treat residents at nursing facility }\end{array}$ & 91 & 88 & 100 \\
\hline Financial concerns of resident or family & 77 & 79 & 77 \\
\hline $\begin{array}{l}\text { Willingness of specialty dentist (like an oral surgeon or denture specialist) } \\
\text { to treat residents at private office }\end{array}$ & 72 & 75 & 72 \\
\hline Willingness of general dentist to treat residents at private office & 68 & 70 & 66 \\
\hline Willingness of general dentist to treat residents at nursing facility & 59 & 55 & 74 \\
\hline Availability of suitable dental treatment space & 54 & 53 & 63 \\
\hline Availability of suitable treatment equipment & 52 & 50 & 59 \\
\hline Transporting resident to dentist or hygienist & 49 & 49 & 55 \\
\hline Time constraints on nursing facility staff & 48 & 49 & 56 \\
\hline Lack of interest in dental care by resident & 44 & 44 & 45 \\
\hline Lack of interest in dental care by resident's family & 43 & 47 & 37 \\
\hline Apathy of dental consultant & 35 & 38 & 33 \\
\hline Apathy of nursing facility staff & 15 & 13 & 19 \\
\hline Apathy of nursing facility administration & 8 & 7 & 9 \\
\hline Other $(n=24)^{\mathrm{b}}$ & 71 & 69 & 83 \\
\hline
\end{tabular}

${ }^{\mathrm{b}}$ Dentists who accept Medicaid $(n=10)$.

${ }^{\text {a }}$ Percentage of respondents who ranked the barrier as 3 or greater. 
needs. In the absence of dentally trained individuals, oral assessment are likely inadequate at identifying oral health needs.

When questioned whether residents identified as needing dental care were likely to receive it, responses indicated that most $(75 \%)$ would. Furthermore, the consequences of delayed treatment were well understood with $93 \%$ indicating that prompt treatment would definitely or probably prevent serious illness. Yet, when asked about the likely time lapse before treatment would be initiated for a hypothetical resident with acute dental discomfort, only $15 \%$ indicated that care would commence within $24 \mathrm{~h}$. Nearly half of respondents thought four or more days would pass before treatment was provided. A small percentage $(4 \%)$ indicated that a dentist would not typically be involved in care at all.

This dichotomy between the perceived importance of responding to oral disease and lengthy periods elapsing before treatment would be provided is puzzling. It may be that the consequences of neglected oral care are acknowledged but not considered as dire. Conversely, the seriousness of the situation may be well understood but the ability of the dental community to respond in a timely fashion may result in unacceptable delays. The second explanation is supported by the majority indicating that this hypothetical resident with acute dental discomfort would be treated in the general dentist's private office, which was identified as a potential barrier to resident oral health by $68 \%$ of responding facilities. However, this explanation is not supported by the nearly $70 \%$ of respondents indicating satisfaction with their facility's response. Treatment of acute dental discomfort within $24 \mathrm{~h}$ is the standard of care in the dental profession. Therefore, the dental and nursing facility professionals appear to have different standards of acceptable response time to the treatment of dental pain. A disparity in the availability of care is also apparent when examining the number of residents receiving dental treatment beyond an examination within the past year. The national average for dental visits by non-institutionalised adults 65 years and older is $56 \%{ }^{22}$. By comparison, survey results indicate that only $28 \%$ of nursing facility residents receive dental treatment beyond an examination with nearly onethird of visits considered emergency care. Within facilities, the majority $(82 \%)$ of oral health monitoring is the responsibility of staff, through either visual assessment or verbal query of the resident. Lack of training in the identification of oral disease by $\operatorname{staff}^{23}$ and the inability of many NH residents to articulate their own needs because of cognitive impairment ${ }^{24}$ brings the adequacy of this type of monitoring, including the evaluation of resident oral hygiene, into question.

A two-part question first assessed the percentage of residents requiring 'supervision or assistance with personal oral hygiene'. Facilities reported that assistance or supervision of personal oral hygiene activities was required for $80 \%$ of residents, corresponding with national findings that $91 \%$ of $\mathrm{NH}$ residents receive personal care services during their stay $^{24}$. The second part of the question queried the number of minutes spent daily 'providing supervision/assistance', with a result of a mean of $11 \mathrm{~min}$. Because the second part of the question did not specifically state 'oral hygiene' assistance, this question was likely interpreted more generally as responses ranged from 0 to $30 \mathrm{~min}$. Thirty minutes of daily assistance just for oral hygiene is highly suspect. Coleman and Watson ${ }^{25}$ reported results of an observational study of morning cares performed in five New York NHs. Routine morning care included dressing, bathing, transfer, toileting, changing incontinence products, oral hygiene and grooming. On average, the time observed that was spent on oral care was between 1 and $5 \mathrm{~min}$ and was provided for only $16 \%$ of residents ${ }^{25}$. Satisfaction with the way the oral hygiene needs of the residents are met was slightly more positive than negative (57\% satisfied vs. $43 \%$ dissatisfied) which would not be the case if residents on average were receiving $11 \mathrm{~min}$ personal oral hygiene assistance.

Directors of nursing identify the lack of willingness of dentists to provide care within their facilities or in private practice as the greatest barrier to the improved oral health status of their residents. Responsibility for day-to-day co-ordination of the dental care plan is often taken by social workers $(44 \%)$ and includes arranging for dental care. This task is difficult given the lack of willingness of dental specialists to treat residents at the $\mathrm{NH}$, the lack of willingness of either general dentists or specialists to treat nursing facility patients in their private office, and the limited number of dentists who accept Medicaid.

This survey demonstrates that a delivery system able to effectively provide dental care to institutionalised elderly in Michigan is lacking. Helgeson, et $a .^{26}$ identified a number of barriers that prevent the profession from providing adequate care. Among them are inadequate facilities and equipment, lack of properly trained oral health providers, lack of integration of oral health care into medical care, and lack of financial resources. In this survey, DONs indicate that the lack of professional 
dental involvement in the identification and treatment of oral disease within the $\mathrm{NH}$ population is the greatest barrier to improved oral health. The population of $\mathrm{NH}$ residents will continue to grow in absolute number due to the ageing of the 78 million 'baby boomers'. Orally, what will differentiate this group from previous cohorts is that they will have had the advantages of better access to dental care, exposure to fluorides and more aggressive preventive care. In short, they will have more teeth and higher expectations (and need) for access to dental care. The inadequacy of the current system can only become more severe in the future unless changes occur.

The $32 \%$ response rate achieved in this survey parallels the response rate obtained by Pyle et al. ${ }^{16}$ in a recent survey of $\mathrm{NH}$ executive directors in Ohio $(33.2 \%)$. However, higher response rates have been achieved by Johnson and Lange ${ }^{18}$ in Nebraska $(64 \%)$ and by Chung et al. ${ }^{14}$ in a survey of managers of Swiss NHs in Geneva (69\%).

Response to the survey was limited despite the use of postcards sent prior to the mailing and as a reminder. The use of a smaller sample with incentives for completion may have yielded a better response rate. The timing of the mailings, near the holiday season, may have negatively impacted survey returns. A shorter, simpler questionnaire would probably have yielded a better return but would have limited the information derived and comparability to data from other surveys. Whether the low response rate reflects a low priority for resident oral health, lack of time or survey overload is unknown.

This was a census study in that all licensed NHs in the state were mailed surveys. Likewise, the Michigan NHs cannot be considered as a random sample in a statistical sense of NHs of the nation. Therefore, statistical tests and precision estimates based on error associated with drawing a random sample from a population can be argued to be inappropriate.

In this study, the primary issue to address is potential non-response bias. With lower response rate comes increased potential for non-response bias, raising the concern that survey responders are not representative of nursing facilities in Michigan. The possible presence of non-response bias can be indicated by assessing available information for differences of responding facilities to all $\mathrm{NHs}$ in Michigan and the nation.

The characteristics of the responding facilities $(n=129)$ are similar in profile to NHs in the nation in average number of beds (107 vs. 105). The average number of beds in Michigan NHs overall is
114. Ethnicity of the residents matches the national average of $88 \%$ Caucasian, which is slightly higher than the average for Michigan NHs (79\%). Fortysix per cent of survey respondents were from forprofit facilities, which is lower than the national $(67 \%)$ and overall state of Michigan $(66 \%)$ percentages. There are small differences between responders and overall state $\mathrm{NH}$ numbers for geographical location, as indicated by zip code related RUCA codes (described in the 'Data management and analysis' section). A slightly higher percentage of responding facilities were rural (26\%) compared to state facilities overall $(22 \%)$. Further RUCA geographical breakdown of facilities were 55\% 'metro', 19\% 'micro', 14\% 'small town' and 12\% 'rural' for responding facilities, compared to $65 \%$ 'metro', $13 \%$ 'micro', $14 \%$ 'small town' and 8\% 'rural' for Michigan NH overall.

While these comparisons show differences, most are small in magnitude, generally not raising concerns of a large non-response bias problem. The largest difference between survey and state $(46 \%$ vs. $66 \%$ ) was in percentage of for-profit facilities. The reason for the lower response rate and the impact of this under-representation of for-profit facilities in our results is unclear. Some possible considerations are that for-profit facilities have a higher percentage of skilled beds with resultant higher turnover. Staff of these facilities with residents whose stays are projected for less than 6 months may not consider oral health as within their purview. In addition, for-profits may have thin staffing margins which may preclude their participation in 'extra' activities such as surveys. Finally, as many for-profits are part of larger corporations, participation in surveys may require clearance by those higher in the corporate chain. If limited staffing is the driving force, then non-response from the for-profit organisations may indicate that oral health concerns are of secondary importance. The impact of this non-response bias would be that survey results would be more positive than the true situation.

Another source of potential non-response bias would be a reluctance to respond based on hesitancy to reveal that the oral health-related activities at the responder's facility were inadequate. However, judging from item response and additional written comments, survey participants perceived and reported inadequacies thereby lessening the concern for this particular source of bias.

Respondent bias may paint a picture that portrays the situation as either better or worse than is actually the case. In this research, respondents may reflect a pool of individuals who were more moti- 
vated to address oral health issues than nonresponders. Therefore results may actually present a picture that is more positive than that observed if participation was more universal. Resultant values would not represent non-responders or overall population values. However, results echo access issues identified in the most recent National Nursing Home Survey ${ }^{27}$ and review articles ${ }^{28}$. In summary, while the potential for non-response bias exists, evaluation and comparison of survey data with available information for non-responding facilities would not indicate the presence of substantial bias.

Any survey instrument is limited by the accuracy of interpretation of terms by the respondents. Further clarification of terminology used in the survey would have added to the overall length, but likely aided in the interpretation. For example, the survey addressed whether a facility had a 'written plan of care' for dental needs. As written, the term could have been interpreted as having a daily oral care plan for individual residents or as having a contractual agreement with a dentist. Both aspects are important but have very different implications for day-to-day attention to oral health vs. episodic treatment events.

\section{Conclusion}

Michigan NHs lack uniformity in oral health policies and practices. Survey results highlight marked differences in the availability of resources directed towards oral health maintenance and the availability of dental care. The lack of dental professional involvement in policy creation, consultation, and services needs to be addressed to improve oral health in Michigan nursing facilities.

\section{Acknowledgements}

The authors are grateful for research support from the following sources: the University of Michigan Geriatric Center/Claude Pepper Older Americans Independence Center Pilot Grant and the University of Michigan Undergraduate Research Opportunity Program (UROP). The authors also thank Sapana Desai (UROP), Kelli McCarrell (UROP) and Emily Pakula (UROP) for contributions to data collection. The authors are grateful to Asuman Kiyak (University of Washington), Douglas Berkey (University of Colorado) and Robert Berg (University of Colorado) for use of survey instruments and assistance. The authors also thank Mary James (University of Michigan Institute of Gerontology) and Sandra Kilde (Michigan Association of Homes and Services for the Aging) for support of this survey.

\section{References}

1. Strahan GW. An Overview of Nursing Homes and their Current Residents. Advance Data from 1995 National Nursing Home Survey; no 280:1-12. Hyattsville, MD: National Center for Health Statistics, 1997.

2. U.S. Census Bureau (2004) U.S. Interim Projections by Age, Sex, Race, and Hispanic Origin. http://www.census.gov/ipc/www/usinterimproj/ (last accessed 31 October 2007).

3. Maupome G, Wyatt CC, Williams PM et al. Oral disorders in institution-dwelling elderly adults: a graphic representation. Spec Care Dentist 2002; 22: 194-200.

4. Locker D. Dental status, xerostomia and the oral health-related quality of life of an elderly institutionalized population. Spec Care Dentist 2003; 23: 8693.

5. Niessen LC, Gibson G. Aging and oral health for the 21 st century. Gen Dent 2000; 48: 544-549.

6. Ellis AG. Geriatric dentistry in long-term-care facilities: current status and future implications. Spec Care Dentist 1999; 19: 139-142.

7. Kiyak HA, Grayston MN, Crinean CL. Oral health problems and needs of nursing home residents. Community Dent Oral Epidemiol 1993; 21: 49-52.

8. Berkey DB, Berg RG, Ettinger RL et al. Research review of oral health status and service use among institutionalized older adults in the United States and Canada. Spec Care Dentist 1991; 11: 131-136.

9. Hawkin RJ. Functional status and untreated dental caries among nursing home residents aged 65 and over. Spec Care Dentist 1999; 19: 158-163.

10. El-Solh AA, Pietrantoni C, Bhat A et al. Colonization of dental plaques: a reservoir of respiratory pathogens for hospital-acquired pneumonia in institutionalized elders. Chest 2004; 126: 1575-1582.

11. Dolan TA, Atchison KA. Implications of access, utilization and need for oral health care by the noninstitutionalized and institutionalized elderly on the dental delivery system. J Dent Educ 1993; 57: 876887.

12. Heylen David. Skilled nursing home residents: assessing their dental needs. J Calif Dent Assn 1986; 14(10): 6-9.

13. Empy G, Kiyak H, Milgrom P. Oral health in nursing homes. Spec Care Dentist 1983; 3: 65-67.

14. Chung JP, Mojon P, Budtz-Jorgensen E. Dental care of elderly in nursing homes: perceptions of managers, nurses, and physicians. Spec Care Dentist 2000; 20: 12-17.

15. Chalmers JM, Hodge C, Fuss JM et al. Opinions of dentists and directors of nursing concerning dental care provision for Adelaide nursing homes. Aust Dent $J$ 2001; 46: 277-283. 
16. Pyle MA, Jasinevicusius TR, Sawyer DR et al. Nursing home executive directors' perception of oral care in long-term care facilities. Spec Care Dentist 2005; 25: $111-117$.

17. Berkey D, Berg R, Smith B. AADR 35th Annual Meeting in Orlando, Florida: oral health care perceptions in U.S. nursing facilities. J Dent Res 2006; 85(Spec Iss A): 74678. http://www.dentalresearch. org.

18. Johnson TE, Lange BM. Preferences for and influences on oral health prevention: perceptions of directors of nursing. Spec Care Dentist 1999; 19: 173180.

19. Ofstehage $\mathbf{J}$. OBRA ' 87 regulations for nursing homes: implications for the dental profession. Northwest Dent 1992; 71: 15-18.

20. Thai PH, Shuman SK, Davidson GB. Nurses' dental assessments and subsequent care in Minnesota nursing homes. Spec Care Dentist 1997; 17: 13-18.

21. Ettinger RL, O'Toole C, Warren $\mathbf{J}$ et al. Nursing directors' perceptions of the dental components of the Minimum Data Set (MDS) in nursing homes. Spec Care Dentist 2000; 20: 23-27.

22. National Center for Health Statistics.Health, United States, 2006. Hyattsville, MD: Public Health Service, 2006.

23. Arvidson-Bufano UB, Blank LW, Yellowitz JA. Nurses' oral health assessments of nursing home residents pre- and post-training: a pilot study. Spec Care Dentist 1996; 16: 58-64.

24. Gabrel CS. Characteristics of Elderly Nursing Home Current Residents and Discharges: Data from the 1997 National Nursing Home Survey. Advance Data from Vital and Health Statistics; 312. Hyattsville, MD: National Center for Health Statistics, 2000.

25. Coleman P, Watson NM. Oral care provided by certified nursing assistants in nursing homes. $J$ Am Geriatr Soc 2006; 54: 138-143.

26. Helgeson MJ, Smith BJ, Johnsen $M$ et al. Dental considerations for the frail elderly. Spec Care Dentist 2002; 22 (Suppl.): 40S-55S.

27. Jones A. The national nursing home survey: 1999 summary. National Center for Health Statistics. Vital Health Stat 2002; 13 (152): 1-1 16.

28. Dolan TA, Atchison K, Huynh TN. Access to dental care among older adults in the United States. $J$ Dent Educ 2005; 69: 961-974.

Correspondence to:

Barbara J. Smith, Geriatric and Special Needs

Populations, American Dental Association, 211

East Chicago Ave., Chicago, IL 60611, USA.

Tel.: 3124402697

Fax: 3124404640

E-mail: smithb@ada.org 